\title{
Smoking in health professionals
}

Smoking in health professionals has been shown to affect their professional life: smoking doctors are less likely than nonsmoking doctors to raise the smoking issue with their patients and although there are not such good data on the issue, it seems likely that a currently smoking health professional will lack credibility with any smokers they may wish to counsel. So before we can expect a reduction in smoking prevalence in a country we need activity in several key areas - regular price rises over and above inflation through taxation, a tobacco advertising ban, restrictions on smoking in workplaces and in public places, a vigorous, well funded and sustained public eduction campaign to inform smokers of the dangers of smoking and treatment to help addicted smokers stop. These are the main components of effective tobacco control campaigns but history suggests that in countries that have seen significant reductions in smoking prevalence in the general population, it fell first in doctors ${ }^{(1)}$. So we should add to this list educating health professionals about smoking and this education should start at the beginning - in medical, nursing, dental and other schools.

It seems logical that before people will believe smoking is dangerous they will need to see health professionals taking the issue seriously. The British experience may be instructive. The British doctors study started in the 1950s. It is a study of all doctors in Britain at the time and follow up continues today. So it has been an extraordinarily powerful study providing data on the relationship between various behaviours - including smoking - and death over more than 50 years. And one of the effects of the study was to raise the issue of smoking in doctors and one of the results of this was that many of them stopped smoking.

It is difficult to be certain what the results of the Baptista Menezes et $\mathrm{al}^{(2)}$ mean and especially how representative they may be of national trends. But they give no grounds for complacency and suggest at the very least that progress on smoking in this group of medical students has stopped, and this is a cause for great concern. If the argument above is accepted then education about smoking and health should be part of the core curriculum of training of students in all health care specialities and 1 would suggest we need to go one step further. They should also all be educated in smoking cessation. From the very beginning of their careers they will encounter patients who are seeing them only because they smoke. This is a challenge. Teaching about smoking cessation is a large undertaking and in many countries the subject is not yet part of the medical (and other) curriculum. But if they are to help their patients stop smoking they will need educating and training in what is now recognised to be a specialist subject requiring considerable knowledge and skills. In 1988 the British Medical Association, for the first time, published a booklet designed to help doctors talk to patients about stopping smoking ${ }^{(3)}$. That was a long time ago and the field has moved on considerably since then but similar initiatives - and much more are needed in Brasil and indeed in other countries.

Brazil currently has a small network of specialised and highly skilled smoking cessation treatment clinics. It is crucial that these are extended to all parts of the country and that their expertise and experience are used to help train the next generation of smoking cessation treatment specialists. But this experience can also be invaluable in helping to train health professionals in the issues if their capacity is increased. Many other resources are available to help health professionals, some through the World Health Organization, for example a training manual on smoking cessation ${ }^{(4)}$ and a free treatment database ${ }^{(5)}$, and some for smokers ${ }^{(6)}$ but in the end reducing smoking prevalence and educating health professionals will require government commitment - including serious funding - and leadership.

\section{Martin Raw}

Universidade Federal de Sao Paulo, Sao Paulo and Guys Kings and St Thomas' School of Medicine, University of London, England.

\section{REFERENCES}

1. Raw M, McNeill A. Tobacco dependence treatment in England (WHO/NMH/TFl/FTC/03.3). In: “Tools for Advancing Tobacco Control in the XXlst century: Success stories and lessons learned." Geneva, World Health Organization, 2003.

2. Baptista Menezes AM, Halla PC, Silva F et al. Tabagismo em estudantes de Medicina: tendencias temporais e fatores associados. J Bras Pneumol; 2004:140-6.

3. Raw M. Help your patient stop. London, British Medical Association \& Imperial Cancer Research Fund, 1988.

4. Helping Smokers Change trainers pack. WHO Europe, July 2001. Available as a PDF on the WHO and ASH websites: www.euro.who.int/eprise/main/WHO/Progs/TOB/Home

5. Raw M. Pare de fumar para sempre. Sao Paulo, Publifolha, 2004. 